\title{
Conceptualizing and measuring culture in international business and management: From challenges to potential solutions
}

\author{
Dan V Caprar ${ }^{1}$, \\ Timothy M Devinney², \\ Bradley L Kirkman ${ }^{3}$ and \\ Paula Caligiuri ${ }^{4}$ \\ ${ }^{1}$ UNSW Australia, Sydney, Australia; ${ }^{2}$ University \\ of Leeds, Leeds, UK; ${ }^{3}$ North Carolina State \\ University, Raleigh, USA; ${ }^{4}$ Northeastern \\ University, Boston, USA

\section{Correspondence:} \\ DV Caprar, School of Management, UNSW \\ Australia Business School, Business Building, \\ Level 5, West Lobby, Sydney, NSW 2052, \\ Australia. \\ Tel: +61 (2) 93855882 ; \\ Fax: +61 (2) 96628531 ; \\ email: dan.caprar@unsw.edu.au
}

\begin{abstract}
Understanding the influence of culture on business operations has been one of the most enduring components of international business (IB) and international management (IM) theorizing and empirical investigation. While several critiques and debates questioned the significant progress made in this domain, the special issue we introduce here is meant to demonstrate that further advancement on how we conceptualize and measure culture is not only needed, but also possible. We provide an overview of past and current approaches in the measurement of culture in IB/IM and the challenges associated with these approaches, and emphasize the important, yet insufficiently acknowledged, link between the theoretical conceptualization of culture and its measurement. We then introduce the four articles included in the special issue and highlight how they break away from the "addiction" to approaches that have been very useful in getting where we are today, but that might not always be useful in advancing knowledge beyond what we already know. Last but not the least, we offer our own perspective on promising directions in conceptually and methodologically rethinking the study of culture in IB and IM.
\end{abstract}

Journal of International Business Studies (2015) 46, I0 I I-1027. doi:10. 1057/jibs.2015.33

Keywords: culture; cultural frameworks; cross-cultural research/measurement issues

\section{INTRODUCTION}

Culture has been one of the most enduring components of international business (IB) and international management (IM) theorizing and empirical investigation. Key topics, such as the multinational enterprise (MNE), internationalization, and cross-country activities, inevitably connect to culture as a broad context or specific factor that cannot be ignored (Leung, Bhagat, Buchan, Erez, \& Gibson, 2005). Culture has been positioned as an antecedent, moderator, and mediator of strategic choices from entry form and mode, patterns of international expansion, cross-border knowledge transfer, to joint venture performance, entrepreneurship, and MNE corporate social responsibility, as well as leadership style, expatriate placement success, and a host of other individual-level outcomes (Kirkman, Lowe, \& Gibson, 2006; Taras, Kirkman, \& Steel, 2010a). More recently, researchers also began to consider culture as a dependent variable, influenced by business activities, especially in the context of cross-border merger and acquisitions and MNEs (Brannen \& Salk, 2000; Caprar, 2011).
Received: 15 July 2015

Accepted: 22 August 2015

Online publication date: 5 November 2015 
Progress in understanding the role of culture in IB/ IM has been significant. However, despite the impressive intellectual gains, there have been those that have highlighted the limitations and gaps in the literature to date. For example, in a review of 93 articles, Tsui, Nifadkar, and Ou (2007) identified major gaps in the theoretical conceptualization and methodology used in many cross-cultural studies, including insufficient examination of the concept of culture itself and inconsistent measurement approaches. Indeed, many scholars question whether we have theoretically clear and effective means of measuring or capturing culture, which, to a large extent, is no doubt due to the well-known difficulty of defining culture in the first place. The Journal of International Business Studies (JIBS) began to directly emphasize the complexity of assessing culture in IB more than a decade and a half ago: Lenartowicz and Roth (1999) argued for a multi-method approach - a recommendation that only a small number of researchers have subsequently followed. Ten years ago, a review of advances in culture and IB (Leung et al., 2005) revealed that most research took a somewhat limited view of culture, dominated by the use of Hofstede's dimensions. The review also triggered an interesting debate (Gould \& Grein, 2009; Leung, Bhagat, Buchan, Erez, \& Gibson, 2011) on the way culture is conceptualized (i.e., national culture vs culture per se) and operationalized (i.e., positivist vs interpretive perspectives), reconfirming that, in spite of the significant and admirable progress on the matter, there is still much work to be done.

In parallel, several articles have evaluated the impact, usefulness, and the limitations of Hofstede's model (see Kirkman et al., 2006 for a review, and McSweeney, 2002 for a representative critique) and provided an insightful exchange between Hofstede and GLOBE (Hofstede, 2006; Javidan, House, Dorfman, Hanges, \& de Luque, 2006; and later Hofstede, 2010). These many commentaries concluded that none of these models is error-free (Smith, 2006) and that alternative models ought to be considered (Earley, 2006). Critiques and refinements of the Hofstede and GLOBE models continued, prompting a special issue of JIBS on improving the quality of cross-cultural research beyond Hofstede and GLOBE (Hofstede, 2010). Even though the articles in that special issue raised important questions and proposed useful improvements in the measurement of culture (e.g., Brewer \& Venaik, 2010; Franke \& Richey, 2010; Maseland \& van Hoorn, 2010; Taras, Steel, \& Kirkman, 2010b; Venaik \& Brewer, 2010; and later Brewer \& Venaik, 2014), there is still a lack of consensus as to the best ways to assess culture (especially beyond Hofstede and GLOBE models).

All scholarly endeavors have periods of rethinking and consolidation and the study of culture is no different. Some of the concerns around the conceptualization and measurement of culture have attempted to be addressed, but persistent conceptual and methodological issues remain that we, as scholars, need to address (Tsui et al., 2007), including the common (but questionable) practice of using country as a proxy for culture (see Brockner, 2003 for a review; Kirkman et al., 2006; Taras et al., 2010a) and heavy reliance of self-report questionnaires (Schaffer \& Riordan, 2003). Tsui et al. (2007) argued for a series of sensible recommendations - for example, attention to intra-cultural variation, use of configuration and cross-level models, polycontextual approaches, and ensuring construct validity beyond back translation and measurement equivalence - that have only rarely been incorporated into standard research practice. Indeed, there is increasing evidence that country might be a less appropriate "container" of culture compared with other potential clustering dimensions. Specifically, using latent class analysis, Taras, Steel, and Kirkman (2015) found many other superior clustering dimensions relative to country, including socio-economic class, professions, age cohorts, historic time periods, and geographic or virtual environments characterized by certain levels of wealth, freedom, equality, instability, and globalization. Reasons for the limitations of country as a container of culture include increased cross-border travel and long-term migration, lower costs of instant communication worldwide, globalization of media and entertainment, and the internationalization of educational systems, and the fact that in many cases national borders are not aligned with ethnic and tribal boundaries (Taras et al., 2015). Finally, in a comprehensive review of all the instruments used to measure culture, Taras, Rowney, and Steel (2009) revealed that the majority of instruments do not deviate much from Hofstede's (1980) model, both in terms of content and measurement approach.

Even though Hofstede's approach to conceptualizing and measuring culture has dominated IB/IM research, another popular value-based model is the one developed by Schwartz. This approach examines the goals or motivations represented by values that will, in turn, propel behavior. Like the Hofstede and GLOBE models, this values-based model has also been the subject of both praise and criticism. Schwartz (2011) himself suggested the need to consider alternative ways of measuring culture. 
While alternative conceptualizations of culture are indeed emerging (e.g., Chao \& Moon, 2005; Hong, Morris, Chiu, \& Benet-Martínez, 2000; Leung et al., 2002), methodologies appropriate for such new conceptualizations are still in their infancy. Even the field of cross-cultural psychology, largely comfortable with psychometric approaches to assessing culture, began to embrace qualitative and mixed methods research (see the special issue of the Journal of CrossCultural Psychology, 2009, Vol. 40/6), mainly as a solution to problems associated with traditional conceptualization and measurement of culture. The management field also began to rediscover alternative approaches (see special issues on ethnography in Organization Research Methods (2010, Vol. 13/2), Journal of Management Studies (2011, Vol. 48/1), and a Journal of International Business Studies special issue on qualitative research in IB $(2011,42 / 5))$ reaffirming the particular relevance of culture and alternative approaches to studying it in IB/IM. Yet many researchers still see a need to quantify culture in order to assess specific hypotheses, and, in that sense, continued efforts to explore best ways to address this need are warranted and imperative for the advancement of the field. This special issue attempts to showcase approaches that are helpful in addressing known issues and stimulate thinking toward new and improved theoretical and empirical approaches to the study of culture in IB/IM. Some of these ideas are captured in the articles published, and we outline others herein. Even though it is impossible to be comprehensive in terms of the theoretical and empirical innovations scholars should consider when thinking about the study of culture, our goal is to promote an agenda in which scholars are willing to challenge conventional and traditional approaches with respect to method and measurement, thereby hopefully introducing a new and different set of lenses on this most important of IB/IM phenomena.

\section{PAST AND CURRENT APPROACHES AND CHALLENGES}

Regarding past and current approaches and challenges, we are not aiming here for an extensive review of conceptualizing and measuring culture; indeed, as noted above, good reviews exist and have generated a solid level of awareness with regard to associated challenges and limitations. Instead, here we summarize key points that are particularly relevant to the field of IB/IM and offer a different perspective that builds upon prior attempts to push the form and nature of the study of culture forward.

\section{The Characterization of Culture}

Fundamentally, culture is characterized in one of three ways in the literature, all of which are group-level constructions. The first and most common characterization of culture is as a group-level reflective construct, in most cases operationalized at the country level. In this sense, culture is discussed as a set of shared characteristics reflected in the behavior of individuals within a specific group - for example, Australians or Germans - and measured by ex ante aggregating individuals' responses to some measurement instrument at that level. However, even though individuals are the point at which data collection occurs, the objective is to derive conclusions at a group level (e.g., researchers compare the responses of one country grouping with another). A second characterization of culture is as an individual-level reflective construct in which the aggregation is endogenous and related to a shared characterization (e.g., social or personal orientation). In this case, culture is measured by aggregating individual responses ex post via statistical procedures aimed at partitioning the responses based on similarity. The third approach is based on creating a country-level formative index in which an overall construct's validity is measured primarily by its predictive ability. Hofstede (1980) and Rokeach (1973) are representatives of the first two approaches, and Kogut and Singh's (1988) formulation of cultural distance is an example of the third.

Much of the culture measurement literature particularly that which views culture as a collective "trait" - draws on Hofstede's $(1980,1991)$ framework, Schwartz's (1992) values, and Hofstede and Bond's (1988) cultural cluster classification of countries (e.g., Dorfman \& Howell, 1988; Ralston, Pounder, Lo, Wong, Egri, \& Stauffer, 2006). Analyzing data from 10 large-scale studies, Ronen and Shenkar (2013) clustered countries based on similarity and dissimilarity in work-related attitudes. At the heart of much of this work are attempts to measure the extent to which two or more locations are similar or different, addressing what Ghemawat (2001, 2004) has asserted should be the central question of IB research: "Why do countries differ?" Theories of the MNE, as a distinct organizational form, implicitly and explicitly explain the MNE "with reference to the challenges and opportunities it faces as a result of distance" (Nachum \& Zaheer, 2005: 247). Early internationalization models promoted the notion of "psychic distance," "defined as the sum of factors preventing the flow of information from and to the market." Kogut and Singh's (1988) cultural distance measure created a one-dimensional index 
of distance between home and host locations that drew on Hofstede's original cultural classification of countries. As Shenkar (2012) recently observed "[f]ew constructs have gained broader acceptance in the IB literature than cultural distance." In the last 10 years alone, Google Scholar contains over 13,000 references to the construct (Zaheer, Schomaker, \& Nachum, 2012).

Even though the specification of a "distance" index, such as Kogut and Singh's (1988), facilitates econometric testing, it "masks serious problems in conceptualization and measurement, from unsupported hidden assumptions to questionable methodological properties, undermining the validity of the construct and challenging its theoretical role and application" (Shenkar, 2001: 520; see also Ricart, Enright, Ghemawat, Hart, \& Khanna, 2004). Traditional distance measures are based on Euclidean distance, which makes the strong assumption that the "differences" in a multidimensional space can be collapsed onto a smaller number of dimensions (in most cases one). However, there are not only many dimensional distances (each dimension against $n-1$ other dimensions) but it may also be the case that shape and form of the different cultures matter (e.g., their density and spread) (see, e.g., Bookstein, 1982, on just one method of comparing similarities in higher dimensional visual data applied in biology and anthropology, and Logan, 2012 for an overview of special models in sociology).

Similarly, research on patterns of and decisions about internationalization by executive teams and board of directors has also challenged the assumptions that cultural distance considerations are key determinants of individual entry decisions and their sequencing within an international strategy (Bingham \& Eisenhardt, 2011; Buckley, Devinney, \& Louviere, 2007). This research highlights the need for richer measures of culture in internationalization studies and consideration of how individuals interpret, understand, and use culture. The focus on cultural differences at the national level (an essential premise of the research on cultural distance) has been criticized for limiting our ability to consider the true nature of the culture construct (Gould \& Grein, 2009).

From a conceptual perspective, the extant work on culture reflects the need to have greater understanding of the psychological logic of its measurement and a clearer articulation of the meaning of the construct as it is operationalized (see Bollen \& Lennox, 1991 for helpful, general guidelines on construct measurement). Yet when we examine the clarity of the construct, it is hard to argue that cultural values would pass common construct requirements, such as the need to be coherently defined, with specified scope conditions and clearly mapped relationships with other constructs (Rossiter, 2011; Suddaby, 2010). As an example of this lack of clarity in culture constructs, the most popular dimension of individualism-collectivism has been operationalized in multiple ways in the literature (Earley \& Gibson, 1998; Oyserman, Coon, $\&$ Kemmelmeier, 2002), with a level of inconsistency even between different versions of Hofstede's instrument. Nor is the construct always clear to researchers themselves. A survey of experts asked to indicate the relevance of common cultural dimensions to culture, in general, and the workplace in particular, revealed limited agreement and questioned the popularity of many such measures (Taras et al., 2009).

Perhaps the greater challenge here is that hidden behind the measurement of culture is a psychological model of what culture entails (Coltman, Devinney, Midgley, \& Venaik, 2008). For example, the reflective approaches to culture (e.g., Hofstede, GLOBE) largely assume that culture is stable and reflected in consistency in behavior that is driven by cultural values or norms. Psychometrically, individual variations in responses to the measures used to capture culture are nothing more than a random, uncorrelated error that has no meaning (this is a mathematical requirement of reflective measurement). Rather ironically, a construct that is meant to account for the importance of an individual-level variation is stripped of its heterogeneity, and hence, a component of its humanness, as aggregating it and assuming a singular structure removes the individualistic component. Formative measures of culture allow for the fact that every individual is unique and can be measured as such. However, formative measures require that every aspect of the structure of culture is defined by the measures being used, which are themselves derived directly by a theoretical formulation of culture that requires that those measures are included in the index. In other words, culture is what the index says it is, no more and no less. That which is important theoretically but excluded from the measurement will, by definition, bias the measure.

Hence when examined collectively, we see a set of logical contradictions in how culture is theorized. Even though culture is understood to be a grouplevel construct that influences an individual (e.g., a commonality of shared experiences) and socializing agents (e.g., language, religion, and geography as 
described in Ronen \& Shenkar, 2013), it is traditionally measured by means that cannot capture the extent to which the individual interprets and internalizes that influence. For example, the four authors of this article cover three different nationalities (i.e., American, Australian, and Romanian), but all were educated in the United States, three were born in the United States, two hold multiple citizenships, and one is female. In responding to survey items associated with culture (e.g., Hofstede, GLOBE, Schwartz), what combination of those influences are we revealing? Is ex ante aggregation meaningful to understand us? In responding to those surveys, how are we influencing the meaning of American, Australian, and Romanian "culture" that is then an influence on others in those "cultures" at some point in the future? Is ex post aggregation meaningful in using our responses to understand others? In addition, if all that mattered were what aspects of those cultures we experienced - for example, where we went to school, how long we lived in a location, our gender - then our "cultures" are distinctly individual, and these experiences represent formative components that drive our individual cultural dimensions. But if this is the case, do we actually know what all those relevant components of that individual "culture" are?

To consider this issue, we should return to cultural anthropology foundations from which IB/IM understands culture (e.g., Boas, 1928). Cultural anthropology acknowledges that culture is socialized, whether as behaviors passed down and reinforced by socializing agents (such as parents, teachers, religious leaders, or government officials) or as responses to collectively shared events and circumstances (such as historical, religious, environmental, or educational experiences). Since many socializing agents and experiences - such as history, government, political economy, and education - are shared by members of a given nation, countries have become the convenient shorthand for cultures. This assumption, as noted previously, can lead to an overestimation of the influence of culture.

It is more accurate to acknowledge that the more socializing agents and life experiences that individuals within a given collective share (e.g., team, profession, organization, region, trading bloc), the greater their likelihood of having a common cultural lens from which judgments, values, preferences, motivations, decisions, and the like are formed (Taras et al., 2015). An approach that connects specific socializing agents and shared experiences to specific IM/IB phenomena of interest would, we believe, bring us closer to understanding the true influence of culture. In this regard, methods that examine the structure of shared experiences (e.g., social network approaches to culture as discussed in Pachucki \& Breiger, 2010) and their meaning (e.g., ethnographic approaches incorporating culture as discussed by Risjord, 2007) should be employed to better understand the role of various socializing agents on both how and why cultural lenses form and what network forms cultures may entail.

Just as our socializing agents change over time and vary in influence, so do the values that result from the socialization. The basic assumption that core cultural values are stable constructs enduring for extended periods of time (e.g., Barkema \& Vermeulen, 1997; Hofstede, 2006) has been called into question by research documenting changes in national cultures (e.g., Ralston, Egri, Stewart, Terpstra, \& Kaicheng, 1999; Ralston et al., 2006), intra-national diversity (Taras et al., 2015; Tung, 2008), and multicultural features of workers in MNEs, often incorrectly assumed to be representative of their national cultures (Caprar, 2011). Moreover, recent research from cognitive psychology suggests a dynamic constructivist approach to culture (Hong et al., 2000; Molinski, 2007), allowing for even intra-individual cultural variation. The more contextual view of culture is in line with thinking in psychology on the interaction of the situation/context with the individual (see, e.g., Cooper \& Withey, 2009) as compared with the more automatic and reflexive view (see, e.g., Wyer, 2014).

\section{The Modeling of Culture}

Beyond the issues concerning formulation of the constructs used in cross-cultural research, there are a series of methodological problems - largely acknowledged, but rarely accounted for in research until relatively recently. For instance, in spite of repeated calls to avoid these pitfalls (e.g., Schaffer \& Riordan, 2003), many researchers still: (a) use country as a proxy for culture; (b) insufficiently articulate and/or account for different levels of analysis; (c) pay limited attention to ensuring equivalence of cross-cultural samples; (d) overly emphasize an etic, vs emic, approach (i.e., assuming universal validity of cultural dimensions while not accounting for specific features of certain cultures); (e) assume, rather than validate, a specific form for the dimensions and construction of culture (e.g., formative vs reflective); and (f) omit much attention to capturing heterogeneity at the individual level.

The most challenging aspect of dominant approaches to measuring culture, however, remains the use of the very popular self-report surveys based 
on stated preferences rated along Likert-type scales. Even though we do not go so far as to say that there is never a place for self-reporting in the assessment of culture, we would argue that an overreliance on a single approach (be it self-report surveys or something else) perpetuates a reductionist view of a complex phenomenon like culture. In addition to the challenges associated with semantics across cultures, there are potential biases stemming from the acknowledged effect of cultural background on response style (e.g., Harzing, 2006) and little accounting for the lack of incentive compatibility and other response biases in survey items individuals may find personally revealing (see, e.g., Devinney, Auger, \& Eckhardt, 2010: 56-59).

In addition, some researchers noted that these scales do not even measure values, but rather marginal preferences (i.e., the importance attached to an objective on top of the current level of satiation; see Maseland \& van Hoorn, 2009). Although some solutions to response biases have been proposed (e.g., combining positive and negative items in a single instrument, the use of within-subject standardization, etc.; Schimmack, Oishi, \& Diener, 2005; Smith, 2004), their capacity to address the shortcomings of Likert-type scales as currently used are limited. Maseland and van Hoorn (2010) suggest the use of "experienced preferences" to derive utility functions associated with variation in certain circumstances (i.e., value-infused contexts), which would better elicit what people really value or not. Even attempts to move to more "scenario-based" questions ultimately rely on some aspect of scalar equivalents that is assumed rather than engineered into the design of the measurement instrument (e.g., König, Steinmetz, Frese, Rauch, \& Wang, 2007).

Indeed, a major driver of the mainstream approach to measuring culture in IB/IM was the convenience of self-report surveys that could produce large data sets. But convenience is often associated with limited capacity in capturing the true complexity of culture; and, consequently, a paradigmatic shift has been proposed toward an attention to patterns (rather than individual dimensions). Lytle, Brett, Barsness, Tinsley, and Janssens (1995) and Tsui et al. (2007) suggested a configurational approach (i.e., the consideration of a set of cultural values), and Chao and Moon (2005) proposed a similar "cultural mosaic" approach. Kitayama (2002) proposed a system approach (i.e., identifying culturally based psychological mechanisms). Von Glinow, Shapiro, and Brett (2004) suggested a polycontextual approach (i.e., consideration for multiple sources of national differences) to better account for the complexity of cultural characteristics and their interrelated dynamics. Even though these approaches are appealing, the fact that most studies have consistently used the same common statistical approaches seems to limit the use of these theoretically interesting ideas, as by their nature they will imply the development of new methodologies; and, the authors do not always suggest how their ideas can be empirically implemented in a meaningful way. Overall, what we have seen to date in the many new approaches proposed is a willingness on the part of scholars to consider alternative methods they hope are at least marginal improvements upon the extant practices with which they are dissatisfied.

Somewhere at the intersection of these different approaches, a sound and, at the same time, practical approach may be the use of behavioral scenarios (Peng, Nisbett, \& Wong, 1997), experimental designs (Leung et al., 2005), and best-worst or discrete choice models (Auger, Devinney, \& Louviere, 2007) along with the application of more sophisticated quantification and data analysis techniques that acknowledge intra-cultural, and even intra-individual, variability. Such advanced methods are still missing in crosscultural research, but they have been finding their way into related areas of research, such as the measurement of social values (Auger et al., 2007; Lee, Soutar, \& Louviere, 2008). This work has revealed three things. First, Likert-type scales can be problematic when it is individuals that are being characterized (Auger \& Devinney, 2007), to the point that they can be completely unrelated to the behaviors they are seeking to capture, particularly when that behavior is dominated by situational factors. Second, the measurement structures of Likert-type scales can be replicated using experimental approaches that remove response-related biases and enhance incentive compatibility (e.g., Lee et al., 2008), create an experimental best-worst variant of the Schwartz value scales. Third, such approaches can be integrated with more sophisticated econometric models that capture a more heterogeneous characterization of culture at both the population and individual level (e.g., Train, 2009).

The debate on what "culture is" continues (see Gould \& Grein, 2009; Leung et al., 2005, 2011), as does the debate on how to measure it. Alternatives to Hofstede's model have been proposed and backed up by large-scale research efforts - for example, the GLOBE Project (House, Hanges, Javidan, Dorfman, \& Gupta, 2004). But these projects, too, are not without flaws (Hofstede, 2006; Javidan et al., 2006). In a comprehensive review of all the instruments 
used to measure culture, Taras et al. (2009) revealed that the majority of instruments do not deviate much from Hofstede's (1980) model, both in terms of content and measurement approach. The 121 instruments identified (and the list is continuously updated, currently at 157) cover 26 dimensions that, with few exceptions, can be grouped under the 5 Hofstede dimensions (see Nardon \& Steers, 2009, for a synthesis of the major cross-cultural value frameworks revealing a similar set of dominant values).

Also, the majority of these instruments use Likerttype scales for capturing cultural values or practices (and sometimes both, with or without clear distinction between the two), applied to individuals but translated into "culture" indices by several methods of aggregation: average or sums of individual item scores are the most common. More "unusual" forms of computation include the percentage of people choosing a category (Triandis, Chen, \& Chan, 1998) and rankings (Rokeach, 1973), with the most atypical method being the sentence completion approach in the "Twenty-statement test" (Kuhn \& McPartland, 1954), in which statements provided next to the prompter "I am ..." are coded in terms of representing certain cultural dimensions.

In terms of recognizing that culture is reflected and expressed at the individual level (van Maanen \& Barley, 1985), there are fundamentally three groups of approaches to modeling individuals as carriers of culture. The first two are econometric approaches and the third is based on qualitative empirical logics. The first is to work via standard parameterized classical econometric models, as is seen in the analysis of discrete choice. For example, the generalized multinomial logit model (GMNL) of Fiebig, Keane, Louviere, and Wasi (2010) allows for the estimation of more sophisticated aggregate models that account for flexible prior distributions of individual heterogeneity (e.g., accounts for both a lognormal scale heterogeneity and a normal preference heterogeneity). Louviere, Street, Burgess, Wasi, Islam, and Marley (2008) offer alternatives for estimating individual-level models that prevent the pulling of parameter estimates toward the population mean, and thus allow us to account for individual heterogeneity to a much greater extent. The historic downside of individual-level models is the need for a sufficient number of observations to estimate the relevant parameters. However, in recognition of this last point, there has been a renewed interest in the modeling of individuals via adaptations of simple methods such as ordinary least squares (OLS) or weighted least squares (WLS) (Louviere et al., 2008) and the use of individual-level prior information has been suggested as a solution for overcoming data limitation issues in individual-level models (Frischknecht, Eckert, Geweke, \& Louviere, 2014).

A second approach is based on Bayesian modeling and finite mixture approaches. These approaches assume that each individual can be characterized in a "model" of their own, and work to estimate those models under differing assumptions. Finite mixture/ latent class modeling views any individual's "model" as unique but that uniqueness can be characterized as a mixture of these "pure" archetypes. Latent class models assume that observations can be sorted into classes, but the classes and their members are unknown to researchers (Greene \& Hensher, 2003). Estimation is based on the empirical determination of the informational value of modeling $N$ individuals as any number of models, $n \leqslant N$, where the model applying to any firm is a weighted average of the $n$ "pure" archetypes. Hence rather than ex post clustering based on correlational similarity, latent class approaches cluster based on the complete form of the model for the individual.

Bayesian modeling generates an individual's model based upon the information unique to the person and that is common to the population of people. Bayesian analysis treats all unobserved variables the same, whether they are parameters, hypothesized relationships, or confidence intervals, based on the concept of conditional probability ( Journal of Management SI, 2015; Kruschke, Aguinis, \& Joo, 2012). Its value is in being able to not just generate individual-level models, but the ability to also directly measure the degree of heterogeneity in those estimates. In other words, it measures not just variation between individuals but variation within the individual's model. From a cultural perspective, a latent class model would view the individual as being a mixture of "pure" cultural archetypes. A Bayesian model would treat each individual as unique but conditional on the population of others, while also being able to reveal to what extent their cultural characterization was more weakly or tightly formed (in other words to what extent they were representative of the estimated cultural characterization).

It is important to note that some researchers seriously challenge the usefulness of a quantitative approach to measuring culture building on traditional approaches to capturing cultures, such as the use of metaphors (Geertz, 1973; Gibson \& Zellmer-Bruhn, 2001). The need to rebalance the etic (mainly represented in survey-based positivist approaches to measuring culture) and the emic 
(Gannon, 2001) approaches reignited interest in alternative methodologies, such as ethnography. JIBS recognizes the value of qualitative approaches (Birkinshaw, Brannen, \& Tung, 2011) as instrumental in providing new and rich theories and insights and a more detailed depiction of culture than what is possible with existing quantitative approaches. In that sense, qualitative research contributes vastly to the understanding of culture and its role in IB/IM (see special issue on this topic in JIBS, 2011, Vol. 42/5), but does not eliminate the need to advance our ways of measuring it.

\section{Linking Theory and Measurement of Culture}

The above summary of approaches and challenges in conceptualizing and operationalizing culture in IB/IM suggests that there are three key areas that will need to be addressed for advancing the field. First, researchers must recognize the fact that there is a critical link between the theoretical conceptualization of culture and its measurement. In other words, the definitions of culture are not independent of the measurement approaches applied; hence, the validity of any conceptualization of culture is actually a joint test of conceptual and methodological appropriateness. Currently, theory is not being effectively matched with methodological opportunities in the sense that researchers are not fully accounting for the joint nature of theory and method. In addition, the empirical measurement of culture has been dominantly nested within a single methodological domain - that is, standard psychometric approaches. Hence the advancement of measurement approaches calls for more innovative cross-domain methodologies that are tightly linked with theory but also allow for empirical approaches that are truly independent/ orthogonalized lenses on the phenomenon of interest. Note that this does not imply that we abandon psychometric approaches or that the work based on such approaches is per se not useful. Our point here is to encourage researchers to think beyond these methods alone and, when possible, apply them in conjunction with other techniques so as to shed more independent light onto culture.

Second, researchers must acknowledge the fact that cultures are composed of individuals, and yet, that the aggregation of the individual measures using mainstream statistical approaches might not always be the best way to arrive at understanding and capturing culture at that level. Hence we must be able to model culture at both the level of the individual and the group in order to recognize the cross-level "nature of the beast" (Tsui et al., 2007:
465). This would allow for not only avoiding the ecological and atomistic fallacies (i.e., unjustified extrapolation of conclusions derived from grouplevel data to the individual level, and the other way around), but also for properly accounting for interaction effects between levels. This, again, requires an advancement of method and an introduction of data collection and statistical approaches more appropriate to multilevel analysis. This also requires a deeper level of understanding of the theoretical mechanisms of how and why socializing agents and shared experiences affect specific IB/IM phenomena of interest because they can occur at different levels beyond country. This would require that IB/IM theorists return to the role socialized values have on their phenomena of interest and learn how (at what level), specifically, these values are shaped. To illustrate, Kluckhohn and Strodtbeck (1961) proposed that we humans have socialized responses to our relationship with time, nature, fellow humans, and also the fundamental motivation for our behavior and the tendency of human nature. A study of the global supply chain would likely find that the socialized values of the organization toward time to far outweigh the socialized values at a country level.

Third, the value of the measurement of culture is in the ability to use it in a predictive manner. Even though general understanding and thick descriptions of culture are extremely useful and informative, identifying ways in which this information can be used for predictive purposes is essential to the advancement of knowledge. To date, we have concentrated dominantly on (a) explaining and characterizing culture and (b) using it as an explanation of dependent variables of interest to $\mathrm{IB} / \mathrm{IM}$ researchers. What we have not addressed enough is culture as a dependent variable (i.e., what type of culture will arise in what type of circumstances; see, for instance, Caprar, 2011; Steel \& Taras, 2010). In other words, one promising area of future work is to look at predicting culture, rather than using culture to predict something else.

\section{OVERVIEW OF THE SPECIAL ISSUE}

The call for papers was received with both enthusiasm and skepticism: the need for better approaches to conceptualizing and measuring culture is largely felt by scholars of IB/IM, but the ongoing issues left many questioning if any further progress is currently achievable. At the same time, the response has been both encouraging - with some impressive innovative and practical ideas - and concerning - with a number of the submissions not significantly departing from what we currently see in the field; that is, 
the belief that attaching some numbers to culture means we have captured it. The process of working through this special issue was indicative in itself that even though significant progress has been made, we still have a long way to go (and that should be exciting for future researchers in this area). We believe, however, that the collection of articles included in this special issue will offer new perspectives and a platform for the much-needed further refinements on how we think about culture in IB/IM.

We received 49 submissions in response to the call for papers. As noted before, in spite of the call for papers specifically requesting a contribution toward new approaches to measuring culture, many worked within existing frameworks. We interpret this as a reflection of the belief some researchers hold that we should accept such issues as inevitable limitations of work that involves the study of culture. Yet other submissions confirmed our and others' belief that improvement in the study of culture is possible: the four articles we selected to be included for publication are certainly a testament to that. The authors have worked hard to address challenging questions and concerns raised by committed reviewers - again, attesting to the fact that the task at hand was not easy, and that researchers like our authors and reviewers are committed to putting in the effort toward improved approaches to understanding culture.

The first two articles offer alternative conceptualizations of culture with direct implications on how we measure it, both building on but also transcending the existing focus on values. In "Values, Schemas, and Norms in the Culture-Behavior Nexus: A Situated Dynamics Framework," Leung and Morris propose a situated dynamics framework approach that integrates the value-based approach with an expanded focus on schemas and norms as additional and important elements of culture. The most important contribution this article makes is not questioning whether values can be used to assess culture; clearly, even with a number of flaws, values can capture certain aspects of culture, at least some of the time. Importantly, their model goes a step further to identify when values play a more important role in determining behavior and other outcomes, based on various situational characteristics (see also Gibson, Maznevski, \& Kirkman, 2009).

For example, values typically play a stronger role in situations involving motivation, such as ethical and identity issues. Motivational situations bring values to the forefront because they tend to align judgments and actions with self-views. On the contrary, in situations involving construal tasks, such as those requiring interpretation of meaning and implications, mental schemas will likely trump values because the former guide sense-making and inferential activities. Finally, for behavioral tasks, or those that require the choice of an appropriate social behavior, norms become more salient than values and schemas in determining individual reactions. Their situated dynamics framework postulates that each of three determinants - values, schemas, and norms - can also work to influence and activate one another, and thus they call into question the aforementioned assumptions about the stability of culture. Leung and Morris argue that it is at the interplay of these three elements that constitutes the most exciting developments in the measurement of culture and its effects. As a result, any assessment of their approach must take into account measures of situational strength and attributes as well as the salience of values, schema, and norms.

In "Mindscapes across Landscapes: Archetypes of Transnational and Subnational Culture," Venaik and Midgley expand and sophisticate the psychometric value-based approach and current operationalization of culture by proposing a focus on the aforementioned cultural archetypes. They first develop a theoretical understanding of the concept, in which cultural archetypes are defined drawing on classic philosophical thought around the idea of a perfect example of a category, or a pure form that represents the characteristic of an object. As such, archetypes are defined as the configuration of values shared by a group, allowing for operationalization of culture that facilitates the departure from the much criticized and outdated view of culture as an attribute of a nation. Cultural archetypes are found at both intra-national and transnational levels, capturing the dual emic-etic nature of culture. Venaik and Midgley also propose and illustrate in detail the use of a methodology aligned with this conceptualization of culture: archetypal analysis, which draws on insights from topology and matrix algebra, as opposed to relying on the typical statistics largely used in social science research. Understanding this method requires a shift in mindset, releasing current paradigmatic assumptions and engaging with different anchors in assessing data - but both the article, and the supplemental technical note, offer extensive explanations and further references for exploring and understanding this rather complex, but useful, methodological approach.

The third article expands the understanding and operationalization of culture by linking the conceptualization and measurement of culture to intra- 
national linguistic and ethnic diversity, via the concept of ethno-linguistic fractionalization (ELF). In the article titled "The Impact of Ethno-Linguistic Fractionalization on Cultural Measures: Dynamics, Endogeneity, and Modernization," John Luiz builds on work from economics and political science, but originating in much earlier efforts to quantify insights from ethnographic work. As in the previous article, a major concern that is addressed here is the need to account for intra-national diversity, along with acknowledgment of cultural dynamics triggered by historical events, modernization, and globalization. ELF is one way of detailing measures of culture and cultural distance - and its relevance is illustrated with the highly fractionalized culture of South Africa - but the concept is certainly relevant not only for understanding contexts that are highly fractionalized, but also for assessing the extent to which such fractionalization is a matter of concern. To a large extent, Luiz's article illustrates the benefit of crossing bridges between fields: by stepping outside of the paradigmatic frameworks inherent to any discipline or field, we are able to integrate different perspectives and knowledge sets toward advanced understanding of complex topics such as culture.

Finally, in "Cultural Intelligence: A Theory-Based, Short Form Measure" by Thomas and 12 other colleagues, we are presented with a simple tool to measure a complex and equally controversial construct - that of cultural intelligence. Even though clearly measuring cultural intelligence does not mean measuring culture, we have included this article in the special issue for three reasons. First, the article provides an example of "culture in use" as opposed to the other articles, which concentrate more on the measurement and meaning of culture. Second, the article provides an excellent example of a measure that looks at an individual-level construct that relates to culture but is itself, culturally invariant. This not only greatly enhances the usability of the instrument but also gives an example about how we can come up with less contextual but very effective means of examining the application of culture. The complexity of IB/IM phenomena makes it very easy to be seduced into believing contingencies matter. In the case of Thomas and colleagues, we have a situation in which they worked very hard to structure a theoretically meaningful instrument that shows that while cultures are different, how individuals interact with cultures may not be (at least at the level they are investigating). Finally, the article presents an example of how researchers should think about building bespoke instrumentation to study important culture-related issues, with a particular eye on where what they are doing fits into the multiple levels at which culture operates. In this regard, Thomas and colleagues provide a nuanced application of psychometric methods that address some of the criticisms discussed earlier.

\section{Key Insights}

The most important learning from the above articles is that progress in conceptualization and measurement of culture is possible, and that such progress will benefit the advancement of knowledge in the field of IB/IM. It is important therefore to "continue the conversation" on how to conceptualize and measure culture, and to constantly remind ourselves of acknowledged limitations in spite of having accepted them as inherent difficulties at a certain point in time. We need to acknowledge that our understanding of culture has advanced dramatically in the last half century, but like all sciences, we need to also look at ways of building on foundational work with new thinking and new approaches. It is also important to continue to re-test and re-question prior research as recent work in psychology has revealed the rather limited replicability of work in the area (Aarts et al., 2015).

The articles in this special issue remind us that measuring cultural values only, despite all that we have learned from doing so, tells a fraction of the complex story that is assessing culture (Leung et al., 2005; Taras et al., 2010a). One can certainly criticize existing measurement approaches to assessing values and focus future work on improving these conventional methods. However, we believe that stopping there is an unnecessary constraint to advancing our understanding. In Leung and Morris's situated dynamics framework, individuals' schema and norms sometimes play more important roles than do values, depending upon various situational contingencies. We have been wedded to the valuesbased approach to measuring culture due in part to the convenience of survey-based assessments but also due to inertia and the reluctance to explore more unconventional ways to measure culture. Indeed, researchers (ourselves included!) have been, in some ways, "addicted" to values-based measures for the last 40 years, and to be fair, we have gained a great deal of understanding about how cultural values influence important outcomes in organizations (Taras et al., 2010a). One thing that is clear here, however, is that even though value-based approaches have got us to where we are today, they are not enough to get us where we could and 
need to be. At the risk of sounding repetitive with other reviews (Taras \& Steel, 2009), the time is now to move beyond simply measuring values via survey responses alone as the dominant way to understand culture. In just one example, Leung and Bond (2004) conceptualized culture with social axioms, or people's beliefs rather than values. Social axioms and other aspects of culture will likely "predict outcomes differently than, or explain unique variance beyond, value-based measures" (Taras et al., 2010a: 432).

The focus on values is certainly related to another important insight: that measurement and conceptualization of culture are tightly linked. This means that sophisticated conceptualizations should inspire improved measurement approaches, rather than allowing methodological limitations to dictate the scope of our thinking about culture. For instance, we may not have the best ways of capturing schemas, but that does not mean we should only talk about values; archetypal analysis may be at odds with some of the methodological thinking we have largely applied so far in social sciences, but that does not mean that we should stick to our known tools and ignore the reality of intra- and transnational archetypes; and, just because ELF may complicate our parsimonious study design (which is only possible under the assumption of homogeneity of cultural groups), it does not mean that we can ignore it and still hope for meaningful insights from our studies. What we (can) measure is certainly useful material - but we must remember that it is not the ideal basis for defining culture.

Finally, the articles in this special issue also indicate that there are multiple opportunities for tackling the difficult task of improving how we conceptualize and measure culture. Improvement can come from considering new content (e.g., aspects of culture that have been previously neglected, such as schemas), exploring new ways of structuring the content (e.g., archetypes), and related new methodological approaches (e.g., archetypal analysis), building on insights from other domains (such as the ELF approach from economics), and perfecting old approaches with an eye for capturing what is essential (e.g., the simplified approach in measuring cultural intelligence). For sure, this does not conclude the range of possibilities - but the key insight here is that the solutions are not to be found in replacing one paradigmatic approach with another, but rather, in allowing for a broad exploration, informed by what we know, but without being wedded to it (see also Earley, 2006; Smith, 2006).

\section{TOWARD A MORE COMPREHENSIVE VIEW OF CULTURE AND ITS MEASUREMENT}

While the above insights are encouraging and, we believe, an important step forward, the task of advancing the study of culture in IB/IM is not yet complete. This is clearly a fact revealed by the small percentage of papers submitted to this issue that were contesting or stretching existing approaches rather than simply applying them in new contexts. There are a number of theoretical and methodological issues that we believe are missing from the discussion that are absolutely paramount if we are going to advance the study of culture and integrate it more meaningfully into $\mathrm{IB} / \mathrm{IM}$ research. In addition, IB/IM is critically situated from a social science perspective in that we work studying phenomena where the variability in antecedents, models, and consequences is highly complex. Therefore we can be a significant driver in terms of conceptual and methodological innovation if we choose to take a riskier approach to the understanding of culture and its implications for international and global phenomena.

\section{Reconceptualizing Culture}

At a conceptual level, there are four absolutely critical issues that scholars need to come to grips with if we are to advance theory. The first one is recognized by researchers but has proven difficult to conceptualize well, as it is very tightly related to measurement; that is, the role of the individual in defining what a culture is and the role of group culture on the individual. Even though many researchers correctly account for the multilevel character of culture (e.g., Autio, Pathak, \& Wennberg, 2013; Steel \& Taras, 2010), they do not readily account for its endogenous nature. Approaches such as Hofstede and GLOBE assume that what one individual reveals in their survey responses does not say anything about any other individual in the cultural group to which they are assigned. Whether the aggregations are ex ante or ex post, those aggregations assume that any one individual is meaningless to the aggregation. However, a more nuanced view of culture would imply that there is simultaneity of effects. Yet we know little if anything about how the individual influences culture, rather than culture influencing the individual or being used as a taxonomy by which we categorize individuals.

The second is related to what we will call "latent culture" and "revealed culture." Revealed culture is represented in behaviors and actions that potentially reveal latent culture (or latent cultural dimensions). In GLOBE and Hofstede, we see a mixture of both latent and revealed culture being tapped, and in 
cultural distance measures we see more of a focus on revealed culture. This issue has two dimensions. The first is similar to discussions in economics and psychology about revealed vs stated preferences; in economics, the distinction between what people say they would purchase as opposed to what they actually purchase (see, e.g., Ben-Akiva et al., 2002; Train, $1986,2009)$. Most of what we see in IB/IM today is stated culture and not revealed culture, with stated culture being used as a best-guess proxy for latent culture (Taras et al., 2010b). However, stated culture is not latent culture but culture that is being revealed not by true behavior but via survey responses; in other words, GLOBE and Hofstede do not represent anything other than culture as revealed by a survey (or culture as contextualized in a survey instrument). Rather than being a generalized notion of culture, it is nothing more than a single contextual lens on an individual's cultural makeup.

The second dimension related to revealed vs latent cultures is whether culture is best understood as a psychological and/or sociological phenomenon and/ or a behavioral phenomenon, and/or in what mixture. To date, most of the work in IB/IM treats culture as a sociological phenomenon, but with psychometrically measured properties. This is important because if we treat it more as a psychological or behavioral phenomenon, we will need to be much more concerned about understanding and measuring it as an individual-level construct - whether or not we choose to aggregate individuals later and how it is that we choose to aggregate them. For example, to date most aggregations of individual measures are done assuming a standard distribution (i.e., a normal distribution characterized by its mean and variance). However, if culture is embodied in a network, and not just a distribution, then the aggregation would need to be quite different so as to capture the key measured components of the network (e.g., centrality, density, distance, tie strengths, etc.).

A third issue in conceptualizing culture is whether we want to view individuals as embodiments of singular or multiple cultures. And, we believe we must consider the multiple culture perspective, especially in the context of IB (Hong et al., 2000). There are many ways to think about this. One is to consider the individual as the embodiment of many latent cultures, each of which - at least in theory can be characterized. Depending on the context in which individuals find themselves, they will evoke one or more of those latent cultures in some combination that will be shown externally as a revealed culture. A second logic would be to view individuals as possessing attributes of many different cultural dimensions, but without discernible latent cultures. When individuals are operating in a specific situation, they create a revealed culture by combining the underlying cultural attribute dimensions needed for that context. What is revealed in behavior (or in survey responses) will likely be the combination of cultural values individuals offer in response to the context. While these two examples of the multicultural individual look similar, they are psychologically very distinct - the former assumes that individuals think in terms of cultures and evoke a "culture" in its entirety; the latter assumes that they think in terms of "cultural" dimensions and only rationalize the collective cultural meaning of those dimensions after making use of them.

Behind this is a fourth issue that arises in response to a view of culture given in the last two points. What is the individual attempting to achieve by invoking a latent culture or a combination of latent cultural attributes in a specific context. One might think that GLOBE's culturally endorsed implicit leadership (CLT) dimensions fit this logic but they do not, as GLOBE assumes that individuals possess these attributes in different mixtures, not that they invoke the different dimensions with different weights under different contexts. Similarly, our notion encompasses, but is different from, the definition of a bicultural (Thomas \& Brannen, 2010) or $n$-cultural individual (Pekerti, Moeller, Thomas, \& Napier, 2015) in that it requires us not only to understand the dimensional structure of latent culture but why culture is evoked, and in the form that it is, to address the issues at hand in the context the individual finds themselves. So, rather than just being satisfied asking "What is culture?", we need to ask the additional question of "What is the individual attempting to achieve in using a specific form of culture, in a specific context?" In this sense, we are arguing that the focal point of culture is not the group but the individual.

\section{Rethinking Culture Methodologically}

In line with a rethinking of the logic underlying our conceptualization of culture, there is a need to open up new methodological lenses. One reason to do this is simply to break the dependence of our concepts from a singular psychometric structure. The second is to align our theoretical developments with the appropriate methodological counterparts.

We noted earlier that there have been discussions about bringing more experimental methodological approaches into the study of culture. This can be 
done in a number of different ways - for example, using designs like discrete choice (e.g., Street, Burgess, \& Louviere, 2005), experimental economics (e.g., Henrich, Boyd, Bowles, Camerer, Fehr, \& Gintis, 2004; Levitt \& List, 2007), policy capturing (e.g., Hobson \& Gibson, 1983), vignettes (e.g., Aguinis \& Bradley, 2014), and so on - that allow researchers to examine more deliberatively both the structure of the dimensions of culture as well as the contextual factors that might lead to latent culture being seen in a revealed context.

In addition, rather than ex post statistically creating dimensions that are orthogonal (e.g., via factor analysis), one can ex ante set up an experimental design in which individuals are forced to make tradeoffs among levels of different cultural dimensions that are truly orthogonal. This would explicitly allow for the creating of unit-less, utility-based measures of the dimensions that become comparable across individuals (in some cases, these measures can even be monetized). Hence rather than just being limited to Likert-type scales that can potentially be confounded by a lack of comparability across individuals and cultures, one can work with utility or monetary measures that are comparable both across individuals and cultures (see, e.g., Auger \& Devinney, 2007; Auger et al., 2007). In addition, more sophisticated multistage or nested experimental designs can be applied that not only vary the trade-offs on cultural dimensions but also nests those trade-offs within specific contexts. Such designs would go a long way toward unpacking the conditions under which latent cultural attributes turn into revealed cultural attributes and allow for the easy construction of individual-level as well as group-level models.

From a more econometric perspective we can build on experimental logics and begin potentially examining latent vs revealed culture. We earlier discussed methodologies such as latent class finite mixture modeling, which do not assume that individuals are simply representative of a population pool but allow individuals to be representative of mixtures of different "pure" models. One can go further than this with Bayesian approaches, which permit the construction of individual-level models that are informed by information about the individual and the population in which that individual resides. These approaches can be extended even further by examining the extent to which individuals use specific models and under what circumstances. In addition, the field is advancing considerably, to the extent that one can apply latent class and Bayesian structures to structural equations modeling to build more complex models that may allow us to capture the multilevel and bidirectional aspects of culture (e.g., Ringle, Wende, \& Will, 2010; Vidaurre, van Gerven, Bielza, Larrañaga, \& Heskes, 2013).

We believe that much more can be done in applying qualitative methodologies in studying culture, particularly how they can inform quantitative results and serve as the basis on which such studies can be designed. Even though there is no doubt value in purely qualitative approaches to culture, our view is that significant value may be obtained from integrating qualitative approaches into larger measurementbased research designs. For example, the IB/IM field has been quite accepting of the dimensions of culture of Hofstede and GLOBE studies. However, we do not know whether or not those dimensions would arise from repeated deep ethnographies.

For example, Lee et al. $(2007,2008)$ showed that they could reformulate and replicate the Schwartz value scale using an experimental best-worst design structure; but, they did not ask the more fundamental question of whether the value structure proposed by Schwartz could be recreated if rebuilt from scratch, nor whether that structure was more predictively valid than some outer grounded alternative. In this regard, we need more grounded research that works to create alternative cultural structures and dimensions that we can subject to testing and formal modeling. In addition, qualitative approaches are excellent ways to get a view of peoples' lived experiences (van Manen, 1990). Even though we might be able to empirically characterize people, no amount of sophisticated modeling will enable us to understand the meaning individuals ascribe to their latent and revealed cultures, nor will we ever be able to address the questions of "why" people invoke specific cultures in specific circumstances. If there is a methodological call on this dimension, we are not just saying we need more multi-method research, but that we also need more research in which multiple lenses are incorporated into a larger integrated research design. This goes beyond just applying methods but truly integrating those methods within a structured design.

Finally, the measurement of culture has been reliant on access to large number of survey respondents. However, we have available today via access to "big data" and social media data, enormous crosscountry, cross-culture, individual-level data that was never imaginable to the scholars developing the original culture instruments. Not only do we have access to millions of minute-by-minute responses on social media, we also have access to geo-location 
data that can tell us something about the context in which this information is being generated and which individuals fall into the social, professional, and locational network of the individual posting or responding to a message. We are not just able to potentially extract latent aspects of an individual's culture - for example, in a manner that Marshall, Lefringhausen, and Ferenczi (2015) did with personality measures based on Facebook posts - but may also be able to examine aspects of revealed culture in use via what individuals do (e.g., what they eat, read, wear, watch on TV, etc.). And, more importantly, rather than it taking us years to generate a limited set of measures from a limited set of countries, we now have the capability to get access to millions of individuals from virtually every country and location in the planet.

\section{CONCLUSION}

We have attempted to accomplish three objectives with this introduction to the special issue. First, we wanted to provide an up-to-date summary of the progress that has been made and the limitations that still exist when it comes to measuring culture. We hope that we have accurately described a situation that has promise, but a promise that has been compromised by a consistent adherence to a "onesize-fits-all" approach to measuring culture (i.e., the values-based approaches of Hofstede, GLOBE, and Schwartz, in particular). Second, we were delighted to share four new articles that we believed had important insights about the next phase of measuring culture. We believe these articles have the potential to encourage new and useful ways of assessing culture in future research. Finally, based on our analysis of gaps and a description of the major

\section{REFERENCES}

Aarts, A. A. et al. 2015. Estimating the reproducibility of psychological science. Science, 349(6251): 943-951.

Aguinis, H., \& Bradley, K. J. 2014. Best practice recommendations for designing and implementing experimental vignette methodology studies. Organizational Research Methods, 17(4): 351-371.

Auger, P., \& Devinney, T. M. 2007. Do what consumers say matter? The misalignment of preferences with unconstrained ethical intentions. Journal of Business Ethics, 76(4): 361-383.

Auger, P., Devinney, T. M., \& Louviere, J. J. 2007. Using bestworst scaling methodology to investigate consumer ethical beliefs across countries. Journal of Business Ethics, 70(3): 299-326.

Autio, E., Pathak, S., \& Wennberg, K. 2013. Consequences of cultural practices for entrepreneurial behaviors. Journal of International Business Studies, 44(4): 334-362.

Barkema, H. G., \& Vermeulen, F. 1997. What differences in the cultural backgrounds of partners are detrimental for international joint ventures? Journal of International Business Studies, 28(4): 845-864. themes from the four articles included here, we provided our own take on even more unique and promising directions for culture assessment. From describing various conceptual approaches - such as latent and revealed cultures - to unique methodological directions - such as discrete choice, experimental economics, policy capturing, vignettes, and Big Data - we hope our special issue really does help to overcome an addiction to the dominant valuesbased approach of the last 40 years. It is at the intersection of these new conceptual and methodological approaches that we believe will make the next 40 years of measuring culture truly dynamic and exciting!

\section{ACKNOWLEDGEMENTS}

We could not let the opportunity of our publishing this special issue on measuring culture pass without mourning the loss of one of the giants in the cross-cultural field, Professor Kwok Leung. Kwok's sudden and untimely passing in May 2015 caught all of us by surprise. His work and colleagueship had tremendous impact on all four of us in terms of our thinking and writing about cross-cultural issues. His influence on the field cannot be underestimated, as his over 20,000 citations on Google Scholar at the time of this writing attests. Ironically, he literally "wrote the book" on cross-cultural measurement and data analysis with his 1997 publication (with Fons Van de Vijver), "Methods and Data Analysis for Cross-Cultural Research," which had enormous impact on how all of us approached conducting research on culture. With all of his important work, and the publication of his article in this special issue with Michael Morris, his influence on the cross-cultural field will continue for a very long time to come. Kwok, you are, and will continue to be, greatly missed.

Ben-Akiva, M., McFadden, D., Train, K., Walker, J., Bhat, C., Bierlaire, M., Bolduc, D., Boersch-Supan, A., Brownstone, D. Bunch, D. S., Daly, A., De Palma, A., Gopinath, D., Karlstrom, A., \& Munizaga, M. A. 2002. Hybrid choice models: Progress and challenges. Marketing Letters, 13(3): 163-175.

Bingham, C. B., \& Eisenhardt, K. M. 2011. Rational heuristics. Strategic Management Journal, 32(13): 1437-1464.

Birkinshaw, J., Brannen, M. Y., \& Tung, R. 2011. From a distance and generalizable to up close and grounded: Reclaiming a place for qualitative methods in international business research. Journal of International Business Studies, 42(5): 573-581.

Boas, F. 1928. Anthropology and modern life. New York: W. W. Norton.

Bollen, K., \& Lennox, R. 1991. Conventional wisdom on measurement: A structural equation perspective. Psychological Bulletin, 110(2): 305-314

Bookstein, F. L. 1982. Foundations of morphometrics. Annual Review of Ecology and Systematics, 13: 451-470. 
Brannen, M. Y., \& Salk, J. 2000. Partnering across borders: Negotiating organizational culture in a German-Japanese joint venture. Human Relations, 53(4): 451-487.

Brewer, P., \& Venaik, S. 2010. GLOBE practices and values: A case of diminishing marginal utility? Journal of International Business Studies, 41(8): 1316-1324.

Brewer, P., \& Venaik, S. 2014. The ecological fallacy in national culture research. Organization Studies, 35(7): 1063-1086.

Brockner, J. 2003. Unpacking country effects: On the need to operationalize the psychological determinants of cross-national differences. In R. M. Kramer, \& B. M. Staw (Eds), Research in organizational behavior. Vol. 25. 333-367. Oxford, UK: Elsevier.

Buckley, P. J., Devinney, T. M., \& Louviere, J. J. 2007. Do managers behave as theory suggests? A choice theoretic examination of foreign direct investment location decision making. Journal of International Business Studies, 38(7): 1069-1094.

Caprar, D. V. 2011. Foreign locals: A cautionary tale on the culture of MNC local employees. Journal of International Business Studies, 42(5): 608-628.

Chao, G. T., \& Moon, H. 2005. The cultural mosaic: A metatheory for understanding the complexity of culture. Journal of Applied Psychology, 90(6): 1128-1140.

Coltman, T., Devinney, T. M., Midgley, D. F., \& Venaik, S. 2008. Formative versus reflective measurement models: Two applications of formative measurement. Journal of Business Research, 61(12): 1250-1262.

Cooper, W. H., \& Withey, M. J. 2009. The strong situation hypothesis. Personality and Social Psychology Review, 13(1): 62-72.

Devinney, T. M., Auger, P., \& Eckhardt, G. M. 2010. The myth of the ethical consumer. Cambridge, UK: Cambridge University Press.

Dorfman, P. W., \& Howell, J. 1988. Dimensions of national culture and effective leadership patterns: Hofstede revisited. In E. G. McGoun (Ed), Advances in international comparative management. Vol. 3. 127-149. Greenwich: JAl Press.

Earley, P. C. 2006. Leading cultural research in the future: A matter of paradigms and taste. Journal of International Business Studies, 37(6): 922-931.

Earley, P. C., \& Gibson, C. B. 1998. Taking stock in our progress on individualism-collectivism: 100 years of solidarity and community. Journal of Management, 24(3): 265-304.

Fiebig, D. G., Keane, M., Louviere, J. J., \& Wasi, N. 2010. The generalised multinomial logit model: Accounting for scale and coefficient heterogeneity. Marketing Science, 29(3): 393-421.

Franke, G. R., \& Richey, R. G. 2010. Improving generalizations from multi-country comparisons in international business research. Journal of International Business Studies, 37(6): 922-931.

Frischknecht, B., Eckert, C., Geweke, J., \& Louviere, J. J. 2014. A simple method for estimating preference parameters for individuals. International Journal of Research in Marketing, 31(1): 35-48.

Gannon, M. J. 2001. Understanding global cultures: Metaphorical journeys through 23 nations. Thousand Oaks, CA: Sage.

Geertz, C. 1973. The interpretation of cultures. New York: Basic Books.

Ghemawat, P. 2001. Distance still matters: The hard reality of global expansion. Harvard Business Review, 79(8): 137-147.

Ghemawat, P. 2004. Global standardization versus localization. In J. A. Quelch, \& R. Deshpandé (Eds), The global market: Developing a strategy to manage across borders 115-145. Hoboken: Wiley.

Gibson, C. B., Maznevski, M. L., \& Kirkman, B. L. 2009. When does culture matter? In R. S. Bhagat, \& R. M. Steers (Eds), Cambridge handbook of culture, organizations, and work 46-70. Cambridge, UK: Cambridge University Press.

Gibson, C. B., \& Zellmer-Bruhn, M. 2001. Metaphor and meaning: An intercultural analysis of the concept of teamwork. Administrative Science Quarterly, 46(2): 274-303.

Gould, S. J., \& Grein, A. F. 2009. Think glocally, act glocally: A culture-centric comment on Leung, Bhagat, Buchan, Erez and Gibson (2005). Journal of International Business Studies, 40(2): 237-245.
Greene, W. H., \& Hensher, D. A. 2003. A latent class model for discrete choice analysis: Contrasts with mixed logit. Transportation Research Part B: Methodological, 37(8): 681-698.

Harzing, A. W. 2006. Response styles in cross-national survey research. International Journal Cross Cultural Management, 6(2): 243-266.

Henrich, J., Boyd, R., Bowles, S., Camerer, C., Fehr, E., \& Gintis, H. 2004. Foundations of human sociality: Economic experiments and ethnographic evidence from fifteen small-scale societies. Oxford: Oxford University Press.

Hobson, C. J., \& Gibson, F. W. 1983. Policy capturing as an approach to understanding and improving performance appraisal: A review of the literature. Academy of Management Review, 8(4): 640-649.

Hofstede, G. 1980. Culture's consequences: International differences in work-related values. Beverly Hills, CA: Sage.

Hofstede, G. 1991. Culture and organizations. New York: McGraw-Hill.

Hofstede, G. 2006. What did GLOBE really measure? Researchers' minds versus respondents' minds. Journal of International Business Studies, 37(6): 882-896.

Hofstede, G. 2010. The GLOBE debate: Back to relevance. Journal of International Business Studies, 41(8): 1339-1346.

Hofstede, G., \& Bond, M. H. 1988. The confucius connection: From cultural roots to economic growth. Organization Dynamics, 16(4): 5-21.

Hong, Y. Y., Morris, M. W., Chiu, C. Y., \& Benet-Martínez, V. 2000. Multicultural minds: A dynamic constructivist approach to culture and cognition. American Psychologist, 55(7): 709-720.

House, R. J., Hanges, P. J., Javidan, M., Dorfman, P. W., \& Gupta, V. 2004. Culture, leadership, and organizations: The GLOBE study of 62 societies. Thousand Oaks, CA: Sage.

Javidan, M., House, R. J., Dorfman, P., Hanges, P., \& Sully de Luque, M. 2006. Conceptualizing cultures and their consequences: A comparative review of GLOBE's and Hofstede's approaches. Journal of International Business Studies, 37(6): 897-914.

Kirkman, B. L., Lowe, K. B., \& Gibson, C. B. 2006. A quarter century of culture's consequences: A review of the empirical research incorporating Hofstede's cultural value framework. Journal of International Business Studies, 37(3): 285-320.

Kitayama, S. 2002. Culture and basic psychological processes Toward a system view of culture. Psychological Bulletin, 128(1): 89-96.

Kluckhohn, F. R., \& Strodtbeck, F. L. 1961. Variations in value orientations. Evanston, IL: Row, Peterson.

Kogut, B., \& Singh, H. 1988. The effect of national culture on the choice of entry mode. Journal of International Business Studies, 19(3): 411-432.

König, C., Steinmetz, H., Frese, M., Rauch, A., \& Wang, Z.-M. 2007. Scenario-based scales measuring cultural orientations of business owners. Journal of Evolutionary Economics, 17(2): 211-239.

Kruschke, J. K., Aguinis, H., \& Joo, H. 2012. The time has come: Bayesian methods for data analysis in the organizational sciences. Organizational Research Methods, 15(4): 722-752.

Kuhn, M. H., \& McPartland, T. S. 1954. An empirical investigation of self-attitudes. American Sociological Review, 19(1): 68-76.

Lee, J. A., Soutar, G. N., \& Louviere, J. J. 2007. Measuring values using best-worst scaling: The LOV example. Psychology \& Marketing, 24(12): 1043-1058.

Lee, J. A., Soutar, G., \& Louviere, J. J. 2008. The best-worst scaling approach: An alternative to Schwartz's values survey. Journal of Personality Assessment, 90(4): 335-347.

Lenartowicz, T., \& Roth, K. 1999. A framework for culture assessment. Journal of International Business Studies, 30(4): 781-798.

Leung, K., Bhagat, R. S., Buchan, N. R., Erez, M., \& Gibson, C. 2005. Culture and international business. Journal of International Business Studies, 36(4): 357-378.

Leung, K., Bhagat, R. S., Buchan, N. R., Erez, M., \& Gibson, C. 2011. Beyond national culture and culture-centricism: A reply 
to Gould and Grein (2009). Journal of International Business Studies, 42(1): 177-181.

Leung, K., \& Bond, M. H. 2004. Social axioms: A model of social beliefs in multi-cultural perspective. In M. P. Zanna (Ed), Advances in experimental social psychology. Vol. 36. 119-197. San Diego: Elsevier Academic.

Leung, K., Bond, M. H., De Carrasquel, S. R., Muñoz, C., Hernández, M., Murakami, F., Yamaguchi, S., Bierbrauer, G., \& Singelis, T. M. 2002. Social axioms: The search for universal dimensions of general beliefs about how the world functions. Journal of Cross-Cultural Psychology, 33(3): 286-302.

Levitt, S. D., \& List, J. A. 2007. What do laboratory experiments measuring social preferences reveal about the real world? Journal of Economic Perspectives, 21(2): 153-174.

Logan, J. R. 2012. Making a place for space: Spatial thinking in social science. Annual Review of Sociology, 38(1): 507-524.

Louviere, I. I., Street, D., Burgess, L. B., Wasi, N., Islam, T., \& Marley, A. 2008. Modeling the choices of individual decisionmakers by combining efficient choice experiment designs with extra preference information. Journal of Choice Modelling, 1(1): 128-163.

Lytle, A. L., Brett, J. M., Barsness, Z. I., Tinsley, C. H., \& Janssens, M. 1995. A paradigm for confirmatory cross-cultural research in organizational behavior. In L. L. Cummings, \& B. M. Staw (Eds), Research in organizational behavior. Vol. 17. 167-214. Greenwich, CT: JAI Press.

Marshall, T. C., Lefringhausen, K., \& Ferenczi, N. 2015. The big five, self-esteem, and narcissism as predictors of the topics people write about in Facebook status updates. Personality and Individual Differences, 85: 35-40.

Maseland, R., \& van Hoorn, A. 2009. Explaining the negative correlation between values and practices: $A$ note on the Hofstede-GLOBE debate. Journal of International Business Studies, 40(3): 527-532.

Maseland, R., \& van Hoorn, A. 2010. Values and marginal preferences in international business. Journal of International Business Studies, 41(8): 1325-1329.

McSweeney, B. 2002. Hofstede's model of national cultural differences and their consequences: A triumph of faith - A failure of analysis. Human Relations, 55(1): 89-118.

Molinsky, A. L. 2007. Cross-cultural code-switching: The psychological challenges of adapting behavior in foreign cultural interactions. Academy of Management Review, 32(2): 622-640.

Nachum, L., \& Zaheer, S. 2005. The persistence of distance? The impact of technology on MNE motivations for foreign investment. Strategic Management Journal, 26(8): 747-767.

Nardon, L., \& Steers, R. M. 2009. The culture theory jungle: Divergence and convergence in models of national culture. In R. S. Bhagat, \& R. M. Steers (Eds), Cambridge handbook of culture, organizations, and work 3-22. Cambridge, UK: Cambridge University Press.

Oyserman, D., Coon, H. M., \& Kemmelmeier, M. 2002. Rethinking individualism and collectivism: Evaluation of theoretical assumptions and meta-analyses. Psychological Bulletin, 128(1): 3-72.

Pachucki, M. A., \& Breiger, R. L. 2010. Cultural holes: Beyond relationality in social networks and culture. Annual Review of Sociology, 36: 205-224.

Pekerti, A. A., Moeller, M., Thomas, D. C., \& Napier, N. K. 2015. $n$-culturals, the next cross cultural challenge: Introducing a multicultural mentoring model program. International Journal of Cross Cultural Management, 15(1): 5-25.

Peng, K., Nisbett, R. E., \& Wong, N. Y. C. 1997. Validity problems comparing values across cultures and possible solutions. Psychological Methods, 2(4): 329-344.

Ralston, D. A., Egri, C. P., Stewart, S., Terpstra, R. H., \& Kaicheng, Y. 1999. Doing business in the 21 st century with the new generation of Chinese managers: A study of generational shifts in work values in China. Journal of International Business Studies, 30(2): 415-428.

Ralston, D. A., Pounder, J., Lo, C. W. H., Wong, Y. Y., Egri, C. P., \& Stauffer, J. 2006. Stability and change in managerial work values:
A longitudinal study of China, Hong Kong, and the US. Management and Organization Review, 2(1): 67-94.

Ricart, J. E., Enright, M. J., Ghemawat, P., Hart, S. L., \& Khanna, T. 2004. New frontiers in international strategy. Journal of International Business Studies, 35(3): 175-200.

Ringle, C. M., Wende, S., \& Will, A. 2010. Finite mixture partial least squares analysis: Methodology and numerical examples. In V. E. Vinzi, W. W. Chin, J. Henseler, \& H. Wang (Eds), Handbook of partial least squares 195-218. Heidelberg: Springer.

Risjord, M. W. 2007. Ethnography and culture. In S. P. Turner, \& M. W. Risjord (Eds), Philosophy of anthropology and sociology 399-428. Amsterdam: North-Holland.

Rokeach, M. 1973. The nature of human values. New York: Free Press.

Ronen, S., \& Shenkar, O. 2013. Mapping world cultures: Cluster formation, sources and implications. Journal of International Business Studies, 44(9): 867-897.

Rossiter, J. R. 2011. Marketing measurement revolution: The C-OAR-SE method and why it must replace psychometrics. European Journal of Marketing, 45(11/12): 1561-1588.

Schaffer, B. S., \& Riordan, C. M. 2003. A review of cross-cultural methodologies for organizational research. Organizational Research Methods, 6(2): 169-215

Schimmack, U., Oishi, S., \& Diener, E. 2005. Individualism: A valid and important dimension of cultural differences between nations. Personality and Social Psychology Review, 9(1): 17-31.

Schwartz, S. H. 1992. Universals in the content and structure of values: Theoretical advances and empirical tests in 20 countries. In M. P. Zanna (Ed), Advances in experimental social psychology. Vol. 25. 1-65. New York: Academic Press

Schwartz, S. H. 2011. Values: Cultural and individual. In F. J. R. Van de Vijver, A. Chasiotis, \& S. M. Breugelmans (Eds), Fundamental questions in cross-cultural psychology. Vol. 25. 1-65. Cambridge, UK: Cambridge University Press.

Shenkar, O. 2001. Cultural distance revisited: Towards a more rigorous conceptualization and measurement of cultural differences. Journal of International Business Studies, 32(3): 519-535.

Shenkar, O. 2012. Cultural distance revisited. Journal of International Business Studies, 43(1): 1-11.

Smith, P. B. 2004. Acquiescent response bias as an aspect of cultural communications style. Journal of Cross-Cultural Psychology, 35(1): 50-61.

Smith, P. B. 2006. When elephants fight, the grass gets trampled: The GLOBE and Hofstede projects. Journal of Internationa Business Studies, 37(6): 915-921.

Steel, P., \& Taras, V. 2010. Culture as a consequence: A multi-level multivariate meta-analysis of the effects of individual and country characteristics on work-related cultural values. Journal of International Management, 16(3): 211-233.

Street, D. J., Burgess, L., \& Louviere, J. J. 2005. Quick and easy choice sets: Constructing optimal and nearly optimal stated choice experiments. International Journal of Research in Marketing, 22(4): 459-470.

Suddaby, R. 2010. Construct clarity in theories of management and organization. Academy of Management Review, 35(3): 346-357.

Taras, V., Kirkman, B. L., \& Steel, P. 2010a. Examining the impact of culture's consequences: A three-decade, multi-level, metaanalytic review of Hofstede's cultural value dimensions. Journal of Applied Psychology, 95(3): 405-439.

Taras, V., Rowney, J., \& Steel, P. 2009. Half a century of measuring culture. Journal of International Management, 15(4): 357-373.

Taras, V., \& Steel, P. 2009. Beyond Hofstede: Challenging the ten testaments of cross-cultural research. In C. Nakata (Ed), Beyond Hofstede: Culture frameworks for global marketing and management 40-61. Chicago, IL: Palgrave Macmillan.

Taras, V., Steel, P., \& Kirkman, B. L. 2010b. Negative practicevalue correlations in the GLOBE data: Unexpected findings, questionnaire limitations and research directions. Journal of International Business Studies, 41(8): 1330-1338. 
Taras, V., Steel, P., \& Kirkman, B. L. 2015. Does country equal culture? Beyond geography in the search for cultural entities. Working Paper, University of North Carolina at Greensboro.

Thomas, D. C., \& Brannen, M. Y. 2010. Bicultural individuals in organizations: Implications and opportunity. International Journal of Cross Cultural Management, 10(1): 5-16.

Train, K. E. 1986. Qualitative choice analysis. Cambridge, MA: MIT Press.

Train, K. E. 2009. Discrete choice methods with simulation. Cambridge: Cambridge University Press.

Triandis, H. C., Chen, X. P., \& Chan, D. K. 1998. Scenarios for the measurement of collectivism and individualism. Journal of CrossCultural Psychology, 29(2): 275-289.

Tsui, A. S., Nifadkar, S. S., \& Ou, A. Y. 2007. Cross-national, crosscultural organizational behavior research: Advances, gaps, and recommendations. Journal of Management, 33(3): 426-478.

Tung, R. L. 2008. The cross-cultural research imperative. Journal of International Business Studies, 39(1): 41-46.

van Maanen, J., \& Barley, S. R. 1985. Cultural organization: Fragments of a theory. In P. Frost, M. Louis, \& L. Moore (Eds), Organization culture 31-53. Newbury Park, CA: Sage.

van Manen, M. 1990. Researching lived experience. London, ON: University of Western Ontario.

Venaik, S., \& Brewer, P. 2010. Avoiding uncertainty in Hofstede and GLOBE. Journal of International Business Studies, 41(8): 1294-1315.

Vidaurre, D., van Gerven, M. A. J., Bielza, C., Larrañaga, P., \& Heskes, T. 2013. Bayesian sparse partial least squares. Neural Computation, 25(12): 3318-3339.

Von Glinow, M. A., Shapiro, D. L., \& Brett, J. M. 2004. Can we talk, and should we? Managing emotional conflict in multicultural teams. Academy of Management Review, 29(4): 578-592.

Wyer, R. S. 2014. The automaticity of everyday life. Advances in Social Cognition. Vol. 10. New York: Psychology Press.

Zaheer, S., Schomaker, M. S., \& Nachum, L. 2012. Distance without direction: Restoring credibility to a much-loved construct. Journal of International Business Studies, 43(1): 18-27.

\section{ABOUT THE AUTHORS}

Dan V. Caprar is a Senior Lecturer at UNSW Australia Business School. He received his PhD in Business Administration from the University of Iowa in the United States. His research, teaching, and consulting are in the areas of culture, leadership, and self-development. Born in Romania, he holds Romanian and Australian citizenships, and lives in Sydney, Australia.

Timothy M. Devinney is University Leadership Chair and Pro Dean of Research and Innovation at Leeds University Business School. His work currently encompasses global social responsibility, advanced research methods, and international strategy and management.

Bradley L. Kirkman is the General (Ret.) H. Hugh Shelton Distinguished Professor of Leadership and Department Head in the Poole College of Management at North Carolina State University. He received his PhD in Organizational Behavior from the KenanFlagler Business School at the University of North Carolina at Chapel Hill. His research interests include international management, leadership, virtual teams, and work team leadership and empowerment. He was born in, and is a citizen of, the United States (blkirkma@ncsu.edu).

Paula Caligiuri is a Distinguished Professor of International Business at Northeastern University (USA) where she researches, teaches, and consults in the areas of Expatriate Management, Global Leadership Development, and Cultural Agility. She directs the CALL Program, a corporate-sponsored international volunteerism program in partnership with the National Peace Corps Association. She holds a PhD from the Pennsylvania State University in IndustrialOrganizational Psychology. 